\title{
Refinement of Technique for Monitoring Radiation Safety of X-Ray Diagnostic Apparatuses
}

\section{E. B. Kozlovskii}

Sanitation regulations SanPiN 2.6.1.1192-03 "Hygienic Requirements for Structure and Use of X-Ray Departments, Apparatuses, and X-Ray Examination” determine radiation monitoring of $\mathrm{X}$-ray apparatuses. According to Table 4.2 of SanPiN, allowable dose power (ADP) in the workplace of group A personnel is $13 \mu \mathrm{Gy} / \mathrm{h}$.

According to SanPiN (Appendix 11), ADP in the workplace of personnel should be regularly monitored. Measured ADP value is normalized to standard working radiation load of the X-ray apparatus (Table 4.1):

$$
D_{n}=D_{u} \cdot W /\left(1800 \cdot I_{u}\right),
$$

where $D_{n}$ is dose power normalized to standard working radiation load of the $\mathrm{X}$-ray apparatus, $\mu \mathrm{Gy} / \mathrm{h} ; D_{u}$ is measured dose power under given conditions, $\mu \mathrm{Gy} / \mathrm{h} ; W$ is working radiation load (Table 4.1), (mA.min)/week; 1800 is group A personnel working time, min/week; $I_{u}$ is anode current during measurement, mA. Eq. (1) is taken from SanPiN (Eq. from appendix 11, p. 12).

The SanPiN method for radiation monitoring of Xray apparatuses implies dose power monitoring. For photographic $\mathrm{X}$-ray apparatuses this requires adequate $\mathrm{X}$-ray dosimeters. In case of short exposure time ( $\sim \mathrm{msec})$ conventional dosimeters introduce significant error in measured dose power. In addition, it is rather difficult to measure anode current $I_{u}$ (necessary to calculate $D_{n}$ ) in photographic X-ray mode.

The history of dose power measurement in radiation control dates back to the first stages of development of domestic X-ray apparatuses. The first domestic X-ray analog apparatuses (DRGZ) were able to measure X-ray dose power rather than dose. Radiation safety control in domestic X-ray chest survey units F-1 and $12 \mathrm{~F} 7$ was implemented in dosimetric mode (photographic working mode of X-ray chest survey unit at anode current $2 \mathrm{~mA}$ ).

In my opinion, the method of dose power monitoring suggested in SanPiN 2.6.1.1192-03 should be com-

All-Russian Scientific-Research Institute for Medical Instrument Engineering, Moscow, Russia; E-mail: vniiimt@comail.ru bined with X-ray dose measurement under standard conditions suggested in SanPiN.

X-Ray apparatuses measure electricity $Q_{\text {meas }}(\mathrm{mA}$. $\mathrm{sec}$ ), whereas exposure is performed under conditions specified in SanPiN (Appendix 12); scattered radiation dose $R_{\text {meas }}(\mu \mathrm{Gy})$ is measured in personnel's workplace.

Electricity $Q_{\text {meas }}$ is set large enough to minimize dosimeter error. Electricity $Q_{\text {meas }}$ should be at mid-range of given $\mathrm{X}$-ray apparatuses.

Given weekly radiation load $W$ specified in SanPiN, total radiation dose per week for given $\mathrm{X}$-ray apparatuses is:

$R_{\text {week }}(\mu \mathrm{Gy} /$ week $)=\frac{W(\mathrm{~mA} \cdot \mathrm{min} / \text { week })}{Q_{\text {meas }}(\mathrm{mA} \cdot \mathrm{sec}) / 60(\mathrm{sec} / \mathrm{min})} \times R_{\text {meas }}(\mu \mathrm{Gy})$.

Dose power reduced to $1 \mathrm{~h}$ is:

$$
\begin{gathered}
D_{n}(\mu \mathrm{Gy} / \mathrm{h})=\frac{R_{\text {week }}(\mu \mathrm{Gy} / \text { week })}{t_{\text {week }}=30(\mathrm{~h} / \text { week })}= \\
=\frac{W(\mathrm{~mA} \cdot \mathrm{min} / \text { week }) \cdot R_{\text {meas }}(\mu \mathrm{Gy}) \cdot 60(\mathrm{sec} / \mathrm{min})}{Q_{\text {meas }}(\mathrm{mA} \cdot \mathrm{sec}) \cdot 30(\mathrm{~h} / \text { week })} .
\end{gathered}
$$

Simple recast gives:

$D_{n}(\mu \mathrm{Gy} / \mathrm{h})=\frac{2[\mathrm{sec} \cdot \mathrm{week} /(\mathrm{min} / \mathrm{h})] \cdot W(\mathrm{~mA} \cdot \mathrm{min} / \text { week }) \cdot R_{\text {meas }}(\mu \mathrm{Gy})}{Q_{\text {meas }}(\mathrm{mA} \cdot \mathrm{sec})}$,

where $R_{\text {meas }}$ is dose measured during measurement of electricity $Q_{\text {meas }}$.

All symbols in this equation are consistent with SanPiN.

The values substituted in Eq. (2) should be observed exactly: measured dose should be in $\mu \mathrm{Gy}(1 \mu \mathrm{Gy}=$ $114 \mu \mathrm{R})$; electricity should be in mA.sec.

Dose power $D_{n}$ calculated from Eq. (2) should be supplemented with radiation safety determination according to SanPiN method. 